\title{
A MARGINALIDADE \\ DA LINGUÍSTICA NA SCI-FI: UMA CRÍTICA A PARTIR DA HISTÓRIA DOS HEPTÁPODES NAS OBRAS DE CHIANG E VILLENEUVE
}

\section{LA MARGINALIDAD DE LA LINGÜÍSTICA EN LA CIENCIA FICCIÓN: UNA CRÍTICA A PARTIR DE LA HISTORIA DE LOS HEPTÁPODES EN LAS OBRAS DE CHIANG Y VILLENEUVE}

\author{
THE MARGINALITY OF LINGUISTICS IN SCI-FI: A CRITIQUE FROM THE STORY OF \\ HEPTAPODS IN THE WORKS OF CHIANG AND VILLENEUVE
}

Luiz Henrique Milani Queriquelli ${ }^{1}$ Universidade do Sul de Santa Catarina UNIASSELVI

RESUMO: Inspirado pela novela História da Sua Vida (1999), de Ted Chiang, e sua contraparte cinematográfica, o filme A chegada (2016), de Denis Villeneuve, roteirizado por Eric Heisserer, sob a supervisão dos linguistas Jessica Coon e Morgan Sonderegger, este ensaio pretende oferecer, em sua primeira parte, uma breve análise de tais obras, destacando alguns de seus méritos e fragilidades; e, complementarmente, em sua segunda parte, com base nas considerações ensaiadas ao longo da análise, apresentar uma reflexão sobre a marginalidade da ciência da linguagem no gênero $s c i$-fi e sobre a própria ficção científica como alternativa para sair dessa condição.

PALAVRAS-CHAVE: Linguística. Ficção científica. Filosofia da linguística.

RESUMEN: RESUMEN: Inspirado en la novela La historia de tu vida (1999), de Ted Chiang, y su contraparte cinematográfica, la película La Llegada (2016), de Denis Villeneuve, con guión de Eric Heisserer, bajo la supervisión de los lingüistas Jessica Coon y Morgan Sonderegger, este ensayo pretende ofrecer, en su primera parte, un breve análisis de tales obras, destacando algunos de sus

Doutor em Linguística (Ufsc), pesquisador na área de estudos românicos e linguística histórica, professor nas universidades UniasselvieUnisul - luizqueriquelli@yahoo.com.br 
méritos y fragilidades; y, complementariamente, en su segunda parte, con base en las consideraciones ensayadas a lo largo del análisis, presentar una reflexión sobre la marginalidad de la ciencia del lenguaje en el género sci-fi y sobre la propia ficción científica como alternativa para salir de esa condición.

PALABRAS-CLAVE: Lingüística. Ciencia ficción. Filosofía de la lingüística.

ABSTRACT: Inspired by Ted Chiang's novel Story of Your Life (1999) and its cinematographic counterpart, Denis Villeneuve's Arrival (2016) (scripted by Eric Heisserer under the supervision of linguists Jessica Coon and Morgan Sonderegger), this essay has a twofold intention. Firstly, it intends to carry out a brief analysis of such works, highlighting some of its merits and weaknesses. Secondly, based on the arguments presented throughout the analysis, it aims to reflect upon the marginality of the science of language in the sci-fi genre, and on science fiction itself, as a solution to escape that condition.

KEYWORDS: Linguistics. Science fiction. Philosophy of linguistics.

\section{INTRODUÇÃO}

A ficção científica (sci-fi), em particular no cinema, mas também na literatura, tende a ser explorada principalmente com vistas ao entretenimento, mas eventualmente alguns autores do gênero são capazes de contribuir de modo significativo para a crítica de teorias e até mesmo de todo um paradigma científico, ao projetar realidades fictícias a partir de certos princípios e proposições teóricas. Exemplos excepcionais no cinema - entre tantos outros dignos de menção - são Laranja Mecânica (A Clockwork Orange, 1971), de Stanley Kubrick, baseado no romance de Anthony Burgess; Ponto de Mutação (Mindwalk, 1990), com roteiro original de Bernt Amadeus Capra; e Sr. Ninguém (Nemo Nobody, 2009), com roteiro original de Jaco Van Dormael. A boa ficção científica tem o poder de mostrar as virtudes e as deficiências de uma teoria (ou até de todo um campo científico) ao radicalizar suas possibilidades, num exercício sério de predição, inerente à própria dinâmica da ciência. Eis o que fazem a novela "História da Sua Vida" (1999), de Ted Chiang, e sua contraparte cinematográfica, o filme "A chegada" (2016), de Denis Villeneuve, roteirizado por Eric Heisserer, sob a supervisão dos linguistas Jessica Coon e Morgan Sonderegger.

A propósito da qualidade desses trabalhos, no presente ensaio pretendo oferecer uma breve análise das obras de Chiang e Villeneuve, destacando alguns de seus méritos e fragilidades, e, complementarmente, a partir das considerações ensaiadas ao longo da análise, farei uma reflexão sobre a marginalidade da ciência da linguagem no gênero da sci-fi e sobre a sci-fi como alternativa para sair dessa condição.

\section{A LIINGUA B DOS HEPTÁPODES}

O enredo das histórias de Chiang e Villeneuve se resume a uma linguista que é convocada pelo exército americano para traduzir os sons emitidos por alienígenas que recém pousaram suas naves na Terra e, assim, comunicar-se com eles para descobrir o propósito da sua visita. Ao aceitar a tarefa, a Dra. Louise Banks rapidamente percebe que tentar decodificar a língua falada dos visitantes seria contraproducente e, então, tenta estabelecer comunicação com signos gráficos. Ela esperava que eles tivessem uma versão escrita da língua falada, isto é, uma língua glotográfica - uma constante no caso das línguas humanas; mas se surpreende ao perceber que seu sistema de escrita era independente da língua falada: tratava-se, em última instância, de uma outra língua, não a versão escrita da primeira. Essa outra língua, a que ela chamou língua B, era semasiográfica. Os heptápodes eram pois, em termos estritos, sujeitos bilíngues, já que usavam com proficiência dois sistemas linguísticos fundamentalmente diferentes - o que por si só já remete a interessantes discussões contemporâneas, como a sugestão de que usuários proficientes da norma culta escrita sejam, em última instância, bilíngues (SIGNORINI, 2002); ou ainda o debate derridiano sobre as línguas escritas como sistemas autônomos, independentes das línguas faladas (MOTA, 1997).

Os heptápodes - assim batizados por serem criaturas de sete membros, semelhantes a um polvo - comunicavam-se visualmente por meio de semagramas parecidos com mandalas. Na novela de Chiang, a personagem da linguista assim explica o que são semagramas: 
No relatório seguinte que apresentei, sugeri que o termo "logograma" era equivocado, porque implicava que cada imagem representava uma palavra escrita, quando, na verdade, os grafismos não correspondiam de jeito nenhum à nossa noção de palavras escritas. Eu também não queria usar o termo "ideograma", devido ao modo como tinha sido usado no passado; sugeri, em vez disso, o termo "semagrama". Grosso modo, um semagrama correspondia a uma palavra escrita nas línguas humanas; tinha significado próprio e, em combinação com outros semagramas, podia formar infinitas frases. Não era uma definição precisa, mas, afinal, ninguém tinha definido satisfatoriamente a palavra "palavra" para línguas humanas. (CHIANG, 2016, p. 130).

No filme, os aliens projetam os semagramas com fluidos corporais numa espécie de espelho; Chiang, na novela, diz que os semagramas são tecidos pelos heptápodes de maneira semelhante a uma teia negra de aranha. No fim das contas, dá na mesma: $\mathrm{o}$ que são teias de aranha senão o resultado de fluidos corporais projetados na forma de estrutura têxtil? Especulações à parte, este é o primeiro ponto forte da narrativa: a língua B dos heptápodes não é um sistema de signos formados por conceito e imagem acústica, mas de signos formados por conceito e imagem gráfica, reproduzidos mediante fluidos corporais que se projetam no ar. À primeira vista, não se diferem muito de uma palavra escrita, de um ideograma, de um ícone ou de um símbolo; mas, em um segundo momento, entendemos que um único semagrama pode representar pensamentos complexos, combinando inúmeras proposições, como numa sentença repleta de subordinações, o que o diferencia sensivelmente desses outros tipos de signo. Terminologias e classificações à parte, isso é, ao mesmo tempo, um elogio ao estruturalismo de Saussure e uma insinuação crítica ao fonocentrismo do senso comum e da própria linguística de tradição saussureana.

O elogio ao estruturalismo saussureano se dá pelo fato de o autor construir uma realidade fictícia, mais especificamente uma língua, que corrobora o princípio segundo o qual qualquer língua é basicamente um sistema de signos que se organiza por oposições, não importa como se dê a representação desses signos (se é por sinais acústicos, por gestos manuais ou, quem sabe, fluidos corporais).

A insinuação crítica ao fonocentrismo é mais sutil, mas não menos aguda. O fonocentrismo, conforme Derrida (2008), pressupõe o privilégio da fala sobre a escrita no que diz respeito a representar o sentido. Ou seja, o sentido é essencial, e tanto a fala quanto a escrita - em última instância - o deturpam, embora a fala o expresse com mais clareza e menos ruído, enquanto que a escrita o deturparia mais. Assim, na visão derridiana, a tradição ocidental tendeu a atribuir à fala o papel de um veículo mais transparente da razão, insinuando que a escrita perturbaria a clareza do significado. Desta forma, o signo gráfico assumiu um carácter periférico na representação do sentido, ao passo que o signo fônico sempre gozou de uma centralidade, daí o nome do fenômeno. Nos termos do autor, o "[...] fonocentrismo [implica] proximidade absoluta da voz e do ser, da voz e do sentido do ser, da voz e da idealidade do sentido" (DERRIDA, 2008, p. 14).

Se a tradição fonocêntrica ocidental subestima a escrita em detrimento da fala, ela sequer considera línguas afônicas. Mais do que desconsiderar as línguas afônicas na construção de inteligência linguística, subjuga-as, considerando-as inferiores muitas vezes. Isso é retratado na narrativa quando os militares, inadvertidamente, assumem que os sons dos aliens sejam sua única língua e, a princípio, desconsideram qualquer alternativa. A linguista no início também cai nessa falácia, mas logo toma consciência do seu equívoco.

$\mathrm{Na}$ realidade, no entanto, temos casos fonocêntricos muito mais lamentáveis. As primeiras abordagens das línguas de sinais de surdos, por exemplo, consideravam-nas formas de linguagem precárias, fruto dos esforços de indivíduos supostamente incapazes de desenvolver linguagem propriamente dita - fônica, por suposto. Isso ficou marcado no debate histórico entre oralistas e gestualistas (LACERDA, 1998), felizmente já superado. Na história em análise, a protagonista alude a isso quando, ao se ver imersa na língua B dos heptápodes, percebe que está pensando em imagens gráficas, e não em imagens acústicas, e então comenta que já tinha ouvido falar que os surdos faziam o mesmo em relação aos seus gestos:

A ideia de pensar em um modo linguístico que não fosse fonológico sempre me intrigou. Tinha um amigo cujos pais eram surdos; ele cresceu usando a Linguagem Americana de Sinais, ASL, e me disse que costumava pensar em ASL em vez de inglês. Eu costumava pensar em como seria ter os pensamentos de uma pessoa codificados manualmente, raciocinar usando um par interior de mãos em vez de uma voz interior. Com o heptápode B eu estava vivenciando algo igualmente estranho: meus pensamentos começavam a se codificar de forma gráfica. (CHIANG, 2016, p. 100). 
A narrativa de Chiang, conforme tenho argumentado aqui, enfatiza a linguística, e o faz não só com suas alusões ao estruturalismo saussureano e ao fonocentrismo, mas também com outras alusões e menções diretas, como ao gerativismo, quando Louise planeja a abordagem da língua alienígena em busca de universais linguísticos, e à teoria dos atos de fala de Austin, quando ela começa a se dar conta da performatividade da língua B. Entretanto, o texto literário dá igualmente bastante destaque à física, incorporada pelo Dr. Gary na novela de Chiang (ou Dr. Ian no filme de Villeneuve), o par romântico da Dra. Louise: ambos se conhecem durante a missão dos heptápodes. Mais particularmente, o destaque à física se traduz na importância dada ao "princípio de Fermat", segundo o qual um raio de luz escolhe ou o caminho mais rápido para atingir seu objetivo, ou o caminho mais longo - nunca uma alternativa intermediária. Isso sugere, entre outras coisas, que um raio de luz seja regido por um princípio teleológico (isto é, sua finalidade orienta seu comportamento), e não um princípio causal (a causa dita o efeito), como a física tradicional tende a analisar os fenômenos físicos em geral. Isso estaria presente, segundo Dr. Gary e os debatedores do princípio fermatiano, em vários outros fenômenos físicos, o que sugere que se pode analisar um fenômeno físico tanto do ponto de vista da sua finalidade quanto do ponto de vista da sua causalidade. O fenômeno é o mesmo, mas a perspectiva muda tudo: muda basicamente toda a maneira como nos orientamos em relação ao tempo. Se nos orientamos com base na finalidade de uma ação, então temos de antever o seu desenvolvimento no tempo e nos situar dentro de um espectro temporal muito mais amplo. Ou seja, isso implica alguma capacidade de prever o futuro ou de alargar a nossa visão temporal. É certamente uma atitude diferente de uma orientação temporal baseada em uma sequência linear de eventos, como implica a abordagem causal da física tradicional. Em outras palavras, a natureza física é a mesma, mas a maneira como a entendemos, nosso pensamento e comportamento em relação a ela, pode mudar a nossa experiência no mundo.

Essa digressão às implicações temporais de uma física regida por um princípio teleológico é essencial para a narrativa, pois a língua $\mathrm{B}$ dos heptápodes reflete essa perspectiva que alarga a visão do tempo. Os heptápodes já sabem tudo o que vão dizer quando começam a grafar (ou tecer) um semagrama, por mais complexo e cheio de sintagmas verbais que ele seja. Eles nunca interrompem a produção de uma sentença, nunca interrompem o seu turno da conversação, reformulando o enunciado por causa de algum evento que se interpôs. Isso, supostamente, porque a maneira como eles encaram o mundo físico lhes dá a vantagem de antever parte do futuro. Ocorre que, quando a Dra. Louise começa a ficar proficiente em heptápode B, ela começa a experimentar essa visão alargada do tempo que o pensamento heptápode permitia. Isso explica, inclusive, o título e a diegese da novela, pois a narrativa transcorre com Louise indo e voltando na "história da sua vida", sugerindo que já a conhecia por inteiro desde que aprendeu a nova língua, embora sua capacidade de predição não lhe desse condições de alterar nada no passado. Ou seja, a língua alienígena induz nela uma nova maneira de pensar. Quem está familiarizado com a ideia já percebeu que aí se encontra a versão forte da hipótese Sapir-Whorf, que diz basicamente a mesma coisa: a língua molda o pensamento (SAPIR, 1949; WHORF, 1956).

Não é a primeira vez que essa teoria é explorada na ficção. George Orwell já tinha feito isso no seu clássico “1984”. Nele, um governo totalitarista cria a "novilíngua", acreditando que, pelo controle sobre a linguagem, seria capaz de controlar o pensamento das pessoas, impedindo que ideias indesejáveis viessem a surgir. A apropriação é satírica e chega a ridicularizar a hipótese Sapir-Whorf, o oposto do que fazem Chiang e Villeneuve, em que ela é levada a sério, como uma possibilidade redentora. Cabe dizer que a novela de Chiang deixa essa hipótese, absolutamente central para o enredo, apenas subentendida (escondida para os leigos), enquanto que no filme de Villeneuve ela é explicitada, virando tema de um dos principais diálogos entre Louise e Ian, precisamente na metade do longa:

Ian: "Estive lendo sobre essa ideia de que se você mergulhar em uma língua não nativa pode reprogramar seu cérebro." Louise: "A hipótese de Sapir-Whorf." Ian: "Uma teoria que diz que a língua determina como você pensa." Louise: "Sim, afeta como você vê tudo." Ian: "Estou curioso. Você sonha na língua deles?" Louise: "Eu tenho tido alguns sonhos. Acho que isso não me desqualifica para o trabalho." Ian: "Você dormiu?" Louise: "Um pouco." Ian: "Fala mandarim? A voz de quem você vai ouvir é do chefe militar chinês."

Esse aspecto - a explicitação da teoria por trás da capacidade preditiva de Louise - é uma das muitas (e positivas) diferenças do roteiro de Heisserer em relação ao texto literário, o que provavelmente deve ser influência dos linguistas que o assistiram. Além disso, no filme, fica claro que a língua B dos heptápodes, que molda o pensamento de forma a alargar a visão do tempo, é em si mesma o presente que eles têm a oferecer aos humanos, e Louise o usa instintivamente para evitar uma catástrofe militar mundial. 
Na novela, a questão da dádiva fica em aberto, e a protagonista apenas experimenta lapsos de visão do futuro enquanto está imersa na interação linguística com os heptápodes, sendo que a história acaba deixando a impressão de que essa ponta ficou solta na trama narrativa.

Voltando à questão da hipótese Sapir-Whorf, ao elogiar o fato de o filme tê-la explicitado e a usado de modo eficiente para o desfecho da trama, não estou dizendo que ele atestou a sua veracidade; muito pelo contrário: "A Chegada" apenas comprova que a versão forte dessa teoria é insustentável, como muitos críticos já o fizeram ao longo de décadas desde a sua proposição (cf. SEUREN, 2013; KAY; KEMPTON, 1984). Para citar o exemplo clássico de Whorf, não é porque a língua dos esquimós-Inuit tem dezenas de palavras para a neve que eles se tornam capazes de distinguir essas tantas variedades de neve, mas o contrário: é a capacidade de discernimento desse objeto desenvolvida por eles que fica registrada nessa diversidade lexical. O mesmo valeria para o heptápode B: não é porque a língua se adapta a uma visão alargada do tempo que os heptápodes têm tal visão, mas o inverso: essa perspectiva inerente ao pensamento deles é que se refletiria na língua. A propósito, não temos em português, por exemplo, dezenas de palavras para a neve basicamente porque temos pouca ou nenhuma experiência com esse fenômeno natural, o que só reforça a antítese em discussão: é a língua que fundamentalmente reflete a nossa cognição, e não o contrário.

De modo paradoxal, a aposta na hipótese Sapir-Whorf enfatizada no filme é, ao mesmo tempo, sua danação e sua salvação: a danação da verossimilhança e a salvação da bilheteria. Embora pertença ao gênero sci-fi, o longa sustenta uma impressionante verossimilhança na maior parte das suas duas horas de duração, algo que só é quebrado no final, quando, num momento catártico, a protagonista usa os superpoderes preditivos conferidos pela língua heptápode para salvar o planeta. De todo modo, para usar os próprios termos técnicos escolhidos por Chiang para representar o intercâmbio entre humanos e aliens na estória, temos um "jogo de soma diferente de zero", em que ambos os lados saem ganhando: Hollywood sai ganhando ao encenar um final fantástico inspirado na versão forte de Sapir-Whorf, apropriado às expectativas de um blockbuster; e a ciência sai ganhando, ao ver a caricatura da versão forte de uma teoria promissora sendo falseada espontaneamente pela ficção - lembremos: uma teoria não falseável não é uma teoria científica, como diria Popper (1959).

Se, por um lado, o filme de Villeneuve supera o texto de Chiang ao desdobrar as implicações da hipótese Sapir-Whorf na narrativa, por outro, ele omite os fundamentos físicos da cosmologia heptápode que resultaram nessa poderosa língua B (a questão do princípio de Fermat). O espectador do filme fica sem saber por que tal língua transforma o pensamento daquela maneira, exceto por um comentário feito de passagem por Louise, em que ela afirma terem os heptápodes uma compreensão não linear do tempo. Assim, na versão cinematográfica a balança está francamente desequilibrada a favor da linguística, ao passo que um dos méritos na novela de Chiang é justamente o equilíbrio entre as ciências que embasam o enredo - além da linguística e da física, que sobressaem, ele também introduz noções da antropologia, ao demonstrar estar ciente da teoria da dádiva (que remete a Mauss e Malinowski), e da química, quando disserta sobre os elementos que compõem a atmosfera do planeta heptápode e sobre as inconsistências da nossa tabela periódica. Esse equilíbrio é de fato digno de aplauso: não há predomínio de exatas sobre humanas (coisa rara em sci-fi), e o autor demonstra estar muito bem informado sobre as noções científicas que utiliza, fazendo um uso preciso delas.

\section{CONSIDERAÇÕES SOBRE A MARGINALIDADE DA LINGUÍSTICA NA SCI-FI E A SCI-FI COMO ALTERNATIVA PARA SAIR DESSA CONDIÇÃO}

Além dos pontos já mencionados, a obra de Villeneuve (mais que a de Chiang) merece atenção por pelo menos outras duas razões: ela coloca a linguística no topo das ciências (algo inédito em blockbusters hollywoodianos) e personifica a ciência numa personagem feminina (algo raríssimo). É comovente ver uma produção desse porte, de orçamento milionário, indicada a Oscar de melhor filme, apostando suas fichas numa ciência marginal, historicamente ignorada pelo gênero. Os filmes de sci-fi sempre valorizaram a física nuclear, entre outras ciências mais "bombásticas", por assim dizer. A chegada mostra para o público leigo que toda ciência de ponta pode ser tão complexa e interessante quanto qualquer ciência pretensamente exata. Em uma das cenas do filme (inexistente na novela original), o físico Ian, interpretado por Jeremy Renner, elogia a linguista Louise, interpretada por Amy Adams, dizendo que ela analisa a língua como se fosse um matemático, e ela o ironiza dizendo que encararia isso como um elogio - uma clara crítica à 
subestimação que os estudiosos de exatas geralmente fazem em relação à linguística, pressupondo que ela seja ciência humana, ainda que, em certos lugares, seja estudada como uma ciência natural-biológica e, em outros, como uma ciência exata. No texto de Chiang, esse ressentimento pela subestimação e pela ignorância do público geral quanto ao que sejam a linguística e os seus métodos sofisticados é timidamente expresso pela personagem Louise, quando ela afirma: "Minha mãe nunca conseguiu entender por que eu não podia ser apenas uma professora de inglês no ensino médio".

Ao invés de engrossar o coro desse ressentimento, porém, penso ser mais proveitoso refletir sobre as razões dessa marginalidade da linguística. O simples fato de brindarmos a proeminência da ciência da linguagem num sci-fi hollywoodiano já é em si um alerta: não faríamos isso se ela estivesse consolidada e se já tivesse sido capaz de se difundir e varrer os mitos que ainda atrapalham a sua comunicação com a sociedade. Por que ela ainda não está plenamente consolidada e por que ainda temos de dar uma introdução à linguística toda vez que alguém nos pergunta o que fazemos? Eu poderia dizer que não há consenso sobre a definição do objeto da nossa ciência, que isso atrapalha muito a consolidação dela e, consequentemente, a sua difusão. Prefiro, porém, focar num outro problema: a endogenia acadêmica do linguista, há décadas observada por Jean-Claude Milner (2012 [1978], p. 113-115):

O que há do lado do linguista? [...] A linguística em si não faz laço social, ela só consegue isso na e pela universidade. Nesse sentido, não existe discurso linguístico, mas somente uma especificação do discurso universitário. [...] O linguista, por definição, estuda e ensina: donde para ele a importância do reconhecimento acadêmico.

O alerta de Milner ainda é atual, e receio que continuará a sê-lo enquanto os linguistas não saírem do seu casulo acadêmico. Ainda somos seres tão exóticos quantos os heptápodes para o público geral. Não é todo dia que um benevolente Ted Chiang (cientista da computação de formação) se presta a estudar com afinco a linguística e trazê-la para o primeiro plano de uma de suas estórias.

Não pretendo aqui oferecer a solução para esse problema. Não creio que haja uma única solução, senão que seja necessário criar "laço social", como diria Milner (2012 [1978], p. 113), e para isso existem muitos caminhos. Publicações populares de propaganda científica, presença sistemática na imprensa e sociedades para difusão da área são algumas estratégias, segundo Couzinet (2009). Já temos alguns esforços nesse sentido no Brasil, a exemplo de linguistas que praticam a divulgação científica, produzindo obras para o público leigo, como Rodolfo Ilari, Sírio Possenti, Ataliba de Castilho, Gabriel de Ávila Othero, Mário Perini, Marcos Bagno, Kanavillil Rajagopalan, entre outros. Tais pesquisadores têm publicado exaustivamente sobre linguística dentro e fora dos muros acadêmicos, e esse é um compromisso que poderia ser assumido com mais engajamento por todos. Outra estratégia é fomentar a ficção científica, promissora por pelo menos duas razões: por injetar seu apreciador numa realidade que a teoria projeta e por proporcionar alternativas para a construção do futuro com informação científica.

A primeira dessas razões pode ser ilustrada pela seguinte analogia de Franknoi (2002, p. 113): "[...] uma coisa é entender em princípio que o dia e a noite na Lua duram cerca de duas semanas terrestres; outra bem diferente é ler sobre um astronauta do futuro abandonado na Lua, para quem isso se torna uma questão de vida ou morte”. Parafraseando Franknoi com vistas à história dos heptápodes, podemos dizer: uma coisa é entender que em teoria uma língua pode reprogramar o pensamento de alguém; outra bem diferente é acompanhar a experiência da Dra. Louise que, ao imergir na língua B, começa a ter visões do futuro. E tal efeito, como tenho dito, pode ter diferentes aproveitamentos: seja para sensibilizar alguém para um problema teórico, ou para fazê-lo perceber o absurdo de uma hipótese. Nos dois casos, é válido.

A segunda razão ecoa nesta reflexão permeada de otimismo pós-moderno de Isaac Asimov (1978, p. 6):

É a mudança, a mudança contínua, a mudança inevitável, que é o fator dominante na sociedade hoje. Nenhuma decisão sensata pode ser tomada por mais tempo, sem levar em conta não só o mundo como é, mas o mundo como será. Os escritores de ficção científica preveem o inevitável e, embora os problemas e as catástrofes possam ser inevitáveis, as soluções não são. As histórias individuais de ficção científica podem parecer triviais para os críticos e filósofos mais cegos de hoje - mas o núcleo da ficção científica, sua essência, tornou-se crucial para nossa salvação se quisermos ser salvos de verdade. 
Salvos os excessos da sua declaração, Asimov chama a atenção para algo que é, em si mesmo, um compromisso da ciência: projetar o futuro e ponderar alternativas para ele. Voltando para a linguística, para a sua necessidade de criar laço social e para as perspectivas da sci-fi nessa empresa, podemos conjeturar inúmeros cenários. Um que me ocorre de pronto remete a uma das teorias da moda na atualidade: o chamado projeto minimalista. Imaginemos um futuro em que o projeto minimalista provou-se verdadeiro e os pesquisadores conseguiram rastrear as especificações que fazem o dispositivo da linguagem acessar diferentes partes do cérebro e integrá-las. Quantos cenários não poderíamos imaginar a partir disso? Uma corrida robótica para a reprodução desse dispositivo; engenheiros da linguagem especulando aperfeiçoamentos; catástrofes e aberrações surgindo por conta disso; a humanidade revivendo dilemas éticos?

Outro cenário que posso conjeturar está ligado à linguística histórica e suas áreas afins (a linguística variacionista, a sociolinguística, os estudos de gramaticalização, a filologia etc.). Imaginemos simplesmente um filme ambientado no Brasil no ano 2120 . Pelas tendências de mudança linguística mostradas pelos estudos atuais, como estará a nossa língua por volta dessa época? O sistema pronominal já estará transformado, mais simplificado no que se refere a pronomes pessoais? E quanto aos demonstrativos? A morfologia verbal terá se transformado? Novos morfemas de tempo, por exemplo, terão surgido ou se consolidado? Como estarão os marcadores discursivos? Marcas de algum dialeto terão ganhado prestígio na língua padrão? Algum contato linguístico terá induzido alguma mudança? Que mudanças prováveis na sociedade terão produzido efeitos na língua? Como estarão as marcas de gênero? As formas de tratamento? Que inovações lexicais serão mais salientes? De onde elas terão vindo? Que tarefa maravilhosa não seria essa para um linguista que fosse chamado a assessorar um autor de sci-fi ou que se aventurasse ele mesmo a escrever nesse gênero? Que propaganda para a linguística não seria um trabalho desses e que benefícios isso não traria para a comunidade da área?

Para encerrar a reflexão, retomo o argumento com que abri este ensaio: embora a ficção científica geralmente se preste a mero entretenimento, ela também é capaz de contribuir para a crítica da ciência projetando cenários. Como tentei argumentar, a boa ficção científica tem o poder de mostrar virtudes e deficiências de uma teoria ao radicalizar suas possibilidades, num exercício sério de predição. Além disso, em se tratando de ciências marginais, como - ouso dizer - é a linguística, fomentar a ficção científica pode ser um caminho para que elas se consolidem e sensibilizem, assim, o público geral para os seus problemas.

\section{REFERÊNCIAS}

ASIMOV, I. Forward. In: HOLDSTOCK, R. (ed.). Encyclopedia of Science Fiction. London: WH Smith Pub., 1978. p. 10-15.

COUZINET, V. Transmitir, difundir: formas de institucionalização de uma disciplina. Perspect. ciênc. inf., Belo Horizonte, v. 14, n. spe, p. 5-18, 2009.

DERRIDA, J. Gramatologia. Trad. Míriam Chnaiderman e Renato Janine Ribeiro. São Paulo: Perspectiva, 2008.

FRAKNOI, A. Teaching astronomy with science fiction: a resource guide. Astronomy Education Review, Tucson, v. 1, n. 2, p. $112-$ 119, jul. 2002/jan. 2003.

KAY, P.; KEMPTON, W. What is the Sapir-Whorf-hypothesis? American Anthropologist, n. 86, p. 65-79, 1984.

MILNER, J.-C. O amor da língua. Trad. Paulo Sérgio de Souza Jr. Campinas: Unicamp, 2012 [1978].

MOTA, S. B. V. da. A Gramatologia, uma ruptura nos estudos sobre a escrita: a Disruption on Written Language Studies. DELTA, São Paulo, v. 13, n. 2, p. 291-313, ago. 1997. 
POPPER, K. The logic of scientific discovery. New York: Basic Books, 1959.

SAPIR, E. Language, culture and personality. Berkeley: University of California Press, 1949.

WHORF, B. L. Language, thought, and reality. Boston: Technology Press of Massachusetts Institute of Technology, 1956.

SEUREN, P. From Whorf to Montague: explorations in the theory of language. Oxford: Oxford University Press, 2013.

SIGNORINI, I. Por um teoria da desregulamentação linguística. In: BAGNO, M. (org.). Linguística da norma. São Paulo: Edições Loyola, 2002. p. 93-127.

\section{(두)(1) $(\circledast$}

